\title{
Weaker bones and white skin as adaptions to improve anthropological "fitness" for northern environments
}

\author{
R. Vieth ${ }^{1}$
}

Received: 13 May 2019 / Accepted: 11 September 2019 / Published online: 6 November 2019

(C) The Author(s) 2019, corrected publication 2019

\begin{abstract}
The vitamin D paradox relates to the lower risk of osteoporosis in people of sub-Saharan African ancestry (Blacks) compared with people of European ancestry (Whites). The paradox implies that for bone health, Blacks require less vitamin D and calcium than Whites do. Why should populations that migrated northward out of Africa have ended up needing more vitamin D than tropical Blacks? Human skin color became lighter away from the tropics to permit greater skin penetration of the UVB light that generates vitamin D. Lack of vitamin D impairs intestinal calcium absorption and limits the amount of calcium that can deposit into the protein matrix of bone, causing rickets or osteomalacia. These can cause cephalopelvic disproportion and death in childbirth. Whiter skin was more fit for reproduction in UV-light restricted environments, but natural selection was also driven by the phenotype of bone per se. Bone formation starts with the deposition of bone-matrix proteins. Mineralization of the matrix happens more slowly, and it stiffens bone. If vitamin D and/or calcium supplies are marginal, larger bones will not be as fully mineralized as smaller bones. For the same amount of mineral, unmineralized or partially mineralized bone is more easily deformed than fully mineralized bone. The evidence leads to the hypothesis that to minimize the soft bone that causes pelvic deformation, a decrease in amount of bone, along with more rapid mineralization of osteoid improved reproductive fitness in Whites. Adaptation of bone biology for reproductive fitness in response to the environmental stress of limited availability of vitamin $\mathrm{D}$ and calcium came at the cost of greater risk of osteoporosis later in life.
\end{abstract}

Keywords Anthropology · Cephalopelvic disproportion · Cesarean section · Childbirth · Environment · Evolution · Natural selection $\cdot$ Osteoporosis $\cdot$ Pelvis $\cdot$ Pregnancy $\cdot$ Ultraviolet light $\cdot$ Vitamin D

\section{Introduction}

Among the people living in temperate regions of the world, those who are of Sub-Saharan-African ancestry (Blacks) tend to possess bone of greater mineral density (if expressed as $\mathrm{g} / \mathrm{cm}^{2}$ ) compared with those of European Ancestry (Whites) [1-3]. Skin color is the obvious difference between Blacks and Whites. Melanin determines skin color, and melanin blocks the ultraviolet light that generates vitamin D in the skin. To generate the same amount of vitamin D, Blacks require up to six times more UVB light energy (acquired through either

\section{R. Vieth}

reinhold.vieth@utoronto.ca

1 Department of Laboratory Medicine and Pathobiology, and Department of Nutritional Sciences, Faculty of Medicine, University of Toronto, Medical Sciences Building, 5th Floor, Room 5253A 1 King's College Circle, Toronto, Ontario M5S 1A8, Canada duration or intensity of light) than do Whites $[4,5]$. In temperate regions, despite their lower serum 25-hydroxyvitamin D $(25(\mathrm{OH}) \mathrm{D})$, Blacks generally have higher bone mineral density (BMD) and higher parathyroid hormone (PTH) than Whites [2]. This is generally referred to as the vitamin D paradox, and in addition to more volumetric bone quantity in Blacks [6], the paradox includes lower incidence of falls, fractures, and osteopenia compared with Whites [7-9].

Since it was so common to find lower serum $25(\mathrm{OH}) \mathrm{D}$ in Blacks, there has been a tendency to think this was normal for them. Powe et al. attributed the vitamin D paradox to lower serum levels of vitamin D-binding protein in Blacks compared with Whites and concluded that despite lower total $25(\mathrm{OH}) \mathrm{D}$, the free, bioavailable $25(\mathrm{OH}) \mathrm{D}$ was similar in Blacks and Whites [10]. However, subsequent reports have shown that the results of Powe et al. were probably an artifact of the assay used for vitamin D-binding protein, which underestimated the polymorphisms of vitamin D-binding protein that are more common in Blacks [11]. Subsequent reports 
showed that vitamin D-binding protein levels and the proportion of serum $25(\mathrm{OH}) \mathrm{D}$ that is bioavailable are not different between American Blacks and Whites. Without supplemental vitamin $\mathrm{D}$, American Blacks do indeed have both lower total and free serum 25(OH)D than Whites [7, 12].

Some have suggested that Blacks are more likely to be lactose intolerant, and that therefore, they have long adapted to a lower calcium requirement. However, lactose tolerance and high dairy intake correlate with agro-pastoral life of population subgroups, and it is not inherently specific to higher latitude or European ancestry [13]. Tolerance for lactose in milk does not distinguish Blacks from Whites; therefore, lactose intolerance does not explain the vitamin D paradox either.

The teleological perspective, that it is normal for Blacks to require less vitamin $\mathrm{D}$, implies that the biology of human populations living in sub-Saharan Africa somehow anticipated an eventual need to accommodate to lower 25(OH)D levels compared with Whites living in the north. But tropical environments have always provided consistent and substantial vitamin D-generating ultraviolet light, for which the skin color of Blacks is, and was appropriately suited [14, 15]. Highly credible data on traditionally living Africans provide a reasonable estimate of the vitamin D nutritional status of early humans. The average $25(\mathrm{OH}) \mathrm{D}$ levels of early humans exceeded $100 \mathrm{nmol} / \mathrm{L}$ (> $40 \mathrm{ng} / \mathrm{mL}$ ) [16, 17]. Those values are not unreasonable, given that they agree with published $25(\mathrm{OH}) \mathrm{D}$ concentrations in healthy non-human primates [18]. Such ancestral levels of vitamin D nutrition are approximately double the 25(OH)D levels reported for modern societies in North America and Europe today. For groups of people in the sun-rich environment of the tropics, there was no mechanistic reason as to why natural selection could have favored a lower requirement for vitamin $\mathrm{D}$ and calcium than those humans who migrated north into Europe.

A recent conference sponsored by the US Department of Health was convened to review the pertinent information on the paradox in the hope of developing insights that might improve musculoskeletal health in all populations [8]. The Institute of Medicine's 2011 dietary guidelines for vitamin D and calcium were quoted as a premise, "...emerging evidence would suggest that there is perhaps a lower requirement for calcium and vitamin D among African Americans relative to ensuring bone health, at least compared with whites." [19]. That statement begs the question: Why would people whose ancestors migrated northward to Europe thousands of years ago have ended up actually needing more calcium and vitamin D than those who remained in the tropics? The appropriate way to develop an answer to the question is to consider the science through a progression that is forward through time, from the perspective of evolutionary biology and anthropology.

Previous attempts to understand the vitamin D paradox have never addressed evolution or anthropology. I contend that more-northerly-suitable human phenotypes must have provided the advantage of making Whites more "fit" for a relatively ultraviolet-and-vitamin D-deficient environment. The hypothesis developed here is, that the health of the pelvis during reproductive years is the key to understanding why the vitamin $\mathrm{D}$ paradox exists.

From the perspective of evolution, it is not helpful to ask, "Why are Black people different from Whites?" A more appropriate approach to understanding differences between Blacks and Whites is to start with the question, "What advantage might there have been for the human populations that migrated out of Africa towards temperate climates to select for bones that — at least in the context of older adults - are of poorer quality?"

\section{Natural selection}

It is genetic makeup that determines the phenotype, and it is natural selection that eventually maximizes the fitness of phenotype to the environment. Like all primates, humans are a species whose biology is best suited to inhabit the tropical latitudes where our species originated [18]. The fitness of a species for an environment is achieved through evolution. The process of evolution involves two components: first, genetic variation; second, natural selection. Genetic variation arises in species because of the accumulation of random imperfections that occur during the replication of genes. Those imperfections can be due to chemicals, radiation, or errors during the copying of genes, such as rearrangement or deletion or insertion of a single nucleotide or of nucleotide sequences. The overall assembly of genes within a species is referred to as a gene pool. Distinct differences in any specific gene from among individuals are referred to as alleles. Alleles may or may not alter the protein encoded by a gene. But as the number of alleles proliferates, the gene pool expands, to the point where some alleles of certain genes may affect an aspect of the phenotype of individuals, and potentially offer certain individuals a specific survival advantage (fitness) over other individuals who do not possess those alleles in their genome.

Natural selection is the process by which those individuals of a species who possess genes that confer greater fitness for their environment survive to the point of having offspring. "Fitness", in the context of natural selection, pertains to the ability to produce more offspring that are viable to the extent that they will likewise give birth to offspring of their own. Natural selection increases the proportion of a population that exhibits a genetic makeup more fit for an environment. Aside from the indirect nurturing role of grandmothering [20], there is no direct mechanism for natural selection beyond the years of childbearing and parenting. Therefore, risk of osteoporosis in older adults cannot have played a meaningful role in natural selection among people migrating northward [21]. 
The original color of the skin of the human species is black, type 6 skin, because Homo sapiens first appeared in SubSaharan, tropical Africa and where that remains the predominant skin type. As human populations migrated away from the equator, both northward and southward, skin color lightened progressively with distance from the equator [22]. This was not evolution in the full sense of the word, because a diverse gene pool had already existed among those persons migrating out of Africa tens of millennia ago. From that pool, genes were selected that maximized fitness - the ability to give birth and to grow healthy offspring. Random mutation continued to affect the gene pools of all human sub-populations, both in sub-Saharan Africa and among those who migrated toward the Arctic.

Away from the tropics, natural selection enriched the gene pool of northward sub-populations with those traits most fit for survival in temperate latitudes. The most widely accepted explanation for how humans accommodated for the progressively diminishing amounts of vitamin D-generating ultraviolet light is referred to as the vitamin $\mathrm{D}$ hypothesis, less duration and intensity of ultraviolet light resulted in less vitamin D production in the skin and thereby lower levels of circulating $25(\mathrm{OH}) \mathrm{D}$, the main index of vitamin D nutritional status. With diminished vitamin D nutrition there was impaired absorption of calcium from the diet, because lack of $25(\mathrm{OH}) \mathrm{D}$ as substrate limits the ability to synthesize the vitamin D-derived hormone, 1,25-dihydroxyvitamin $\mathrm{D}(1,25(\mathrm{OH}) 2 \mathrm{D})$ that increases efficiency of calcium absorption from food. Together, the lack of vitamin D and lack of absorbed calcium resulted in osteoid that was not completely mineralized in infants and children $[18,23]$. Moreover, 1,25(OH)2D improves the skeletal microarchitecture of bone via a direct mechanism, independent of its function to improve intestinal absorption of calcium [24].

During adolescence, vitamin D intake has site-specific associations with bone mineral density, particularly at the pelvis and spine [25]. It has been shown in a double-blind randomized controlled clinical trial, that in girls, supplementation with $2000 \mathrm{IU} /$ day of vitamin D increases not only bone mineral density but also improves the structural geometry of the hip [26-28].

\section{Pregnancy and the pelvis}

Rickets can misshape a girl's pelvis to a fatal degree [29], and a healthy pelvis was the determining feature that drove natural selection among human populations as they migrated into temperate latitudes (Fig. 1). Without rickets to drive selection for lighter skin color, the entire human population would almost certainly have remained deeply pigmented, with type 5 or 6 skin [14].
The growing pelvis is a far more complex bony structure than are the long bones or the vertebrae. The pelvis comprises seven centers of primary ossification that are mineralized by age 9 years. However that stage is followed by a series of secondary chondrification and ossification events that are not completed until about 35 years of age [31]. Most of the volume of the pelvic bone consists of trabecular bone that is sandwiched between thin shells of cortical bone. The structural, "sandwich behavior" of pelvic cortical bone means that this cortical bone carries a stress load that is fifty-fold bigger than pelvic trabecular bone inside it [32]. There are 21 different muscles that attach to the pelvic bone, and those convey additional support and strength for the pelvis [32]. Since vitamin D deficiency causes proximal muscle myopathy [28], it is reasonable to postulate that vitamin D deficiency-related muscle weakness around the pelvis can add to the stress forces that can deform pelvic bone, and together with unmineralized osteoid, vitamin D-related myopathy may contribute to risk of cephalopelvic disproportion.

I have not been able to find any reports describing the biomechanics of the rachitic or osteomalacic pelvis. Published research about the pelvis has been directed at understanding pelvic fractures due to impacts or at understanding the pelvis to optimize the quality of hip replacements [33]. What we do know relates to the structure of the normal pelvis. The limited biomechanical data about the pelvis focus on the forces related to standing and walking [32] or for use in designing hip prostheses. No biomechanical analyses have been directed at the forces of the sitting positions that probably impose the kinds of forces that could diminish the width of the pelvic opening. Future research to test the present pelvic hypothesis for the vitamin D paradox could involve finite element analysis of pelvic bone modeling, with adjustments made for defects related to areas unmineralized osteoid of rickets and osteomalacia.

If rickets develops in adolescents, the long bones may appear to be normal, but radiologic examination of the pelvis will reveal excessive osteoid that is treatable if vitamin $\mathrm{D}$ is available [34]. If rickets or osteomalacia continue through pregnancy, then deformation of the pelvis becomes progressively worse with each pregnancy and lactation, due to the mineral demands of the growing fetus and infant [35]. Recent epidemiological data from the USA are consistent with this, in that Black women (but not White women) develop a progressively higher risk for cesarean delivery with each pregnancy [36] (Table 1).

Research into osteoporosis has focused on the vertebrae and long bones. But ironically, the iliac crest is the classic site for bone biopsy. Ethical reasons preclude comparative sampling from other bone sites in humans, so it may not be reasonable to assume that histology of the pelvis is representative of all cortical and trabecular bones throughout the body. Most of what we know about the relationship between vitamin D 
Fig. 1 Drawing of the pelvis of a healthy adult female (left) compared with a photograph of the pelvis of a woman with untreated rickets and osteomalacia (right) published by Maxwell et al. [30] (with permission). Both views are topdown. Natural child-birth was not possible with the narrow, misshapen pelvis at the right that illustrates an extreme example of cephalopelvic disproportion

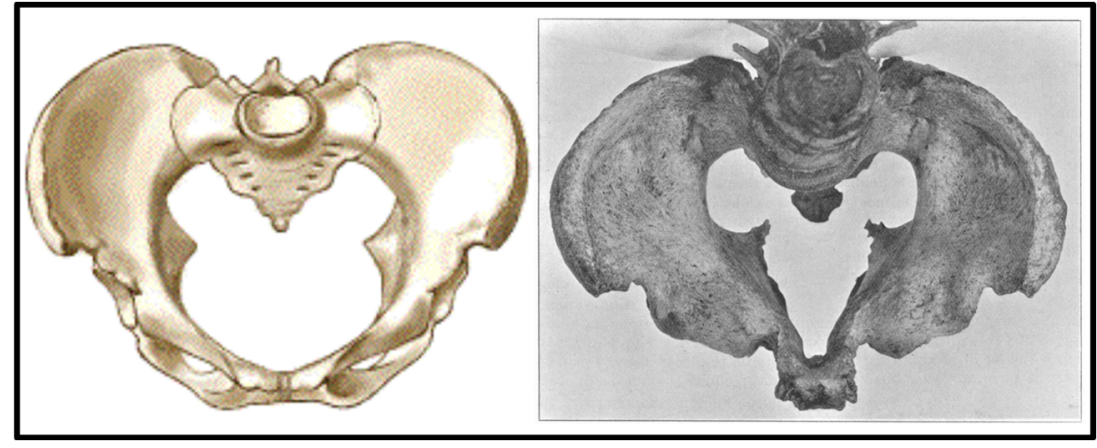

nutritional status and unmineralized osteoid in a normal population comes from the work of Priemel et al. who obtained blood samples and biopsied iliac crest from hundreds of victims of accidental deaths in Germany [50]. They showed a steady decline in pelvic osteoid - improved mineralizationas serum 25(OH)D levels increased toward $75 \mathrm{nmol} / \mathrm{L}$. Beyond $75 \mathrm{nmol} / \mathrm{L}$, there was virtually no evidence of unmineralized osteoid. These data by Priemel et al. were highlighted by the Institutes of Medicine in their latest assessment of dietary requirements for calcium and vitamin D [19]. But oddly, the evidence pertaining to the pelvis was ignored when it came to the final recommendation for vitamin D [51, 52]. If the findings of Priemel et al. are true, then risk of unmineralized osteoid extends well into the range of serum $25(\mathrm{OH}) \mathrm{D}$ recommended by the Institutes of Medicine, 50 $125 \mathrm{nmol} / \mathrm{L}$, with risk particularly high if dietary calcium is limited.

Through the natural course of pregnancy, serum 25(OH)D levels are far higher in Black women who live a traditional lifestyle consistent with that of early humans in Sub-Saharan Africa, than are the $25(\mathrm{OH}) \mathrm{D}$ levels of White women who live in Europe or North America. Luxwolda et al. reported serum $25(\mathrm{OH}) \mathrm{D}$ through pregnancy in five East African ethnic groups: Maasai, Hadzabe, Same Sengerema, and Ukerewe. The most striking observation was that despite no supplemental vitamin $\mathrm{D}$, their serum $25(\mathrm{OH}) \mathrm{D}$ increased during the

Table 1 Risk of cesarean birth and features of bone and mineral metabolism for people of European ancestry (Whites) as compared with people of subSaharan African ancestry (Blacks)

Cesarean birth risk

-White women in the USA are at lower risk of cesarean delivery, after correcting for sociodemographic confounders [36-40]

-White women have no increased risk of cesarean delivery with multiple pregnancies,

while risk of cesarean delivery increases with multiple pregnancies in Black women [36]

-White women have a wider pelvis in relation to stature height [41]

Osteoporosis risk

-White women have lower bone mineral density (BMD) based on cross-sectional area $\left(\mathrm{g} / \mathrm{cm}^{2}\right)[1-3]$

-White men have lower BMD $\left(\mathrm{g} / \mathrm{cm}^{2}\right)$ for the whole body, tibia, hip, and femoral neck [42]

-White children have less tibial cortical bone density $\left(\mathrm{g} / \mathrm{cm}^{3}\right)$ strength despite having higher levels of bone-promoting factors of physical activity, dietary calcium intake, and serum 25(OH)D concentrations [43]

-Before puberty, vertebral trabecular number, thickness, and true BMD (volumetric, $\mathrm{g} / \mathrm{cm}^{3}$ ) do not differ by race or gender. Racial differences emerge during puberty when male and female Blacks increase BMD from 250 to $260 \mathrm{mg} / \mathrm{cm} 3$ in Tanner stage 1 to $330-34040 \mathrm{mg} / \mathrm{cm}^{3}$. In contrast, male and female Whites increase BMD by half that amount, from 250 to $260 \mathrm{mg} / \mathrm{cm} 3$ in Tanner stage 1 to $290-300 \mathrm{mg} / \mathrm{cm}^{3}[6,44]$.

-White women have longer hip axis length [45]

-White men and women have less favorable bone microarchitecture.

By young adulthood, their bone exhibits diminished plate-like morphology and less trabecular axial alignment [46] .

-White men have smaller bones with thinner cortices and less bending strength than Black men. [42]

-White men and women have weaker trabeculae and, in males, less bone quantity, and poorer bone quality. [47]

-White women have faster mineral apposition rate in iliac biopsy [48]

-Whites have higher levels of markers of bone turnover (osteocalcin, CTx,OHPro, BAP) [49]

-Whites have lower PTH [2, 49]

-Whites have greater skeletal response to PTH [49]

-Whites have lower levels of 1,25(OH)2D [49]

-Whites have a faster rate of bone loss [49] 
second and third trimesters of pregnancy, with concentrations averaging $150 \mathrm{nmol} / \mathrm{L}$ [16]. Among African women living in their tropical environment, without a vitamin D supplement, the sharp increase in serum $25(\mathrm{OH}) \mathrm{D}$ attains double the serum levels typically seen among White women in North America and Europe, where 25(OH)D levels actually trend downward during pregnancy $[53,54]$. If women in sub-Saharan Africa had extremely high vitamin D nutrition, as seen from our present perspective, there must surely have been selection pressure to adapt northwardly migrating populations to somehow accommodate to lower amounts of ultraviolet lightderived vitamin $\mathrm{D}$.

Skin color is the obvious adaptation to accommodate to diminishing ultraviolet light; however, there are many qualitative differences in muscuskeletal features between Black and Caucasian adults, different bone densities, different microstructure, different rates of bone formation and different rates of osteoporosis (Table 1). Another likely adaptation is the comparatively wider pelvis of Arctic and European populations, compared with those of southern latitudes [41]. A wider pelvis is a more robust phenotype, allowing for some osteomalacic deformation of the pelvis while lowering the risk of cephalopelvic disproportion. Although the preceding are plausible features that may prevent cephalopelvic disproportion, they do not explain the cause of the differences in osteoporosis risk between Blacks and Whites.

\section{Bone fibril strength}

What survival advantage might there be to the diminished quantity and quality of adult bone in northern populations? The answer must surely have something to do with the "fitness" in the sense of the phenotypes that maximize the number of viable births. The quality of bone in the adult is secondary to the characteristics of bone that minimize the risk of rickets and osteomalacia. I contend that natural selection would have increased prevalence of those phenotypes that prevented deformation of the pelvis of a growing girl or young woman (Fig. 1).

Features of White bone evident from Table 1, such as less bone quantity $[1,42,43,47,48]$ and faster mineralization of osteoid [48] serve as advantages that prevent pelvic deformation. This is because less bone growth through the initial step of matrix formation requires less calcium to mineralize it fully, making for more efficient use of the calcium that is available. Proper mineralization is important for bone strength at both the microfibril as well as at the nanofibrillar levels [55]. Recent research has characterized the biomechanical strength of rachitic bone in the hypophosphatemic mouse model, compared with the normal bone of wild-type mice [56]. Karunaratne et al. studied the functional link between altered bone quality (reduced mineralization) and abnormal fibrillar- level mechanics using real-time synchrotron X-ray nanomechanical imaging. They demonstrated a nanostructural mechanism in which incompletely mineralized fibrils of rachitic mice are more extensible and less stiff, i.e., exhibiting greater strain and bendability. "It is clear that the unmineralized or partially mineralized fibrils will exhibit a much larger strain than the fully mineralized fibril for the same force." [56]. Similarly, Dardenne et al. demonstrated severely impaired biomechanics of unmineralized long bone from rachitic and osteomalacic mice, and showed that correction of the vitamin D deficiency caused a rapid improvement in bone stiffness toward normal [57]. Earlier work by Turner et al. showed that the osteomalacia caused by excessive fluoride intake in rats coincided with diminished bone strength as assessed by the three-point-bending test [58]. In the macroscopic context, what we know from animal studies is that incompletely mineralized bone is weaker, and much more flexible.

If these findings are taken in the context of the human pelvis, we know that incompletely mineralized bone will bend. If left untreated, this will result in severe pelvic deformation, to the point that natural childbirth is impossible [30] (Fig. 1). Pregnancy and breastfeeding impose strong demands on the skeleton to supply calcium to the growing fetus and infant. With poor vitamin D and calcium nutrition, osteomalacia causes a progressive deformity of the pelvis with each pregnancy, progressively increasing risk of death in childbirth $[30,34-36]$.

\section{Early Life}
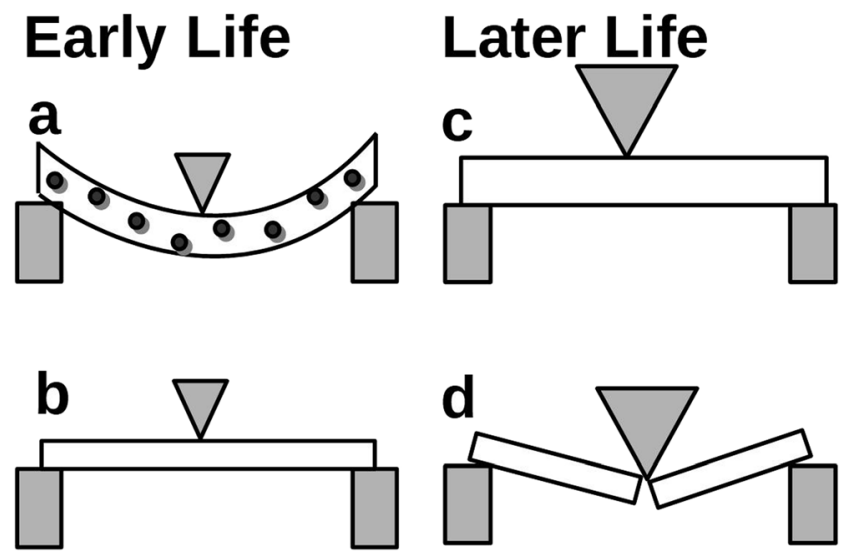

Fig. 2 Illustrative images of biomechanical behavior of bone of Blacks (top) compared to Whites (bottom). The horizontal white rectangles represent long-bone samples, resting on solid blocks. The triangles represent a stressing force, whose magnitude is represented by the size of the triangle. a Thicker bone, but whose stiffness, or resistance to bending is diminished during growth, because of an inability to acquire sufficient calcium to the bone, leaving zones of unmineralized osteoid, represented by the circles. $\mathbf{b}$ Sample of thinner bone, but where osteoid is fully mineralized. With the smaller amount of total bone, less calcium is needed for the more complete mineralization that makes bone resistant to bending. Later in life, once all bone is suitably mineralized, $\mathbf{c}$ the thicker bone resists an amount of stress that causes $\mathbf{d}$ failure and fracture of the thinner bone 
A key lesson, based on the laboratory-animal work, is that in terms of bone stiffness, it is better to have less bone, but bone which is fully mineralized, instead of more bone that contains too many regions of incompletely mineralized osteoid (Fig. 2a, b). Many of the distinguishing features of Whites are things that make for more efficient use of available calcium, because more rapid and more complete mineralization of osteoid improve stiffness of the pelvis, preventing its deformation, cephalopelvic disproportion, and death in childbirth.

The pelvis is the most important bone in the context of the evolutionary fitness of the species. At the pelvis, less bone, but bone which was fully mineralized would have been superior to a situation with more bone, but where that bone contained unmineralized osteoid. The benefit for the species of a pelvis made up of stiffer bone, albeit with less total amount of bone, was a higher probability that infants could be delivered vaginally. However, the eventual consequence of less bone for the older adult would be lower bone mineral density and weaker bones (Fig. 2c, d). The mystery of the vitamin D paradox may lie in the paradox that some of the adaptations that prevented deformation of the pelvis in Whites also resulted in matured skeletal bone that is of lesser quantity and quality. Adaptation to less vitamin $\mathrm{D}$ involved a more rapid mineralization of bone along with less bone accrual; these things optimized stiffness of pelvic bone to accommodate for limited availability of calcium absorbed from diet.

\section{Bone density in the modern context}

The perspective presented here predicts that compared with Whites at identical margins of low calcium and low vitamin D nutrition, Black children would be more likely to develop rickets, while Black women during their childbearing years would be more prone to osteomalacia. Given the same restricted calcium and vitamin D nutrition, Black and White women can possess the same total amount of mineralized bone. However, because of their larger total volume of bone, Blacks at the margins of low calcium and low vitamin D would be expected to have a lower mineral content per unit volume of bone. Dual energy X-ray absorptiometry (DEXA) which measures amount of mineral per cross-sectional area of bone exposed to it $\left(\mathrm{g} / \mathrm{cm}^{2}\right)$ cannot distinguish between osteoporosis and the osteomalacia that contributes to bone bendability. Likewise, volumetric bone density based on computed tomography $\left(\mathrm{g} / \mathrm{cm}^{3}\right)$ has not been capable of distinguishing impaired mineralization from porosity. However, newer micro-CT technology is becoming capable of estimating matrix mineral density [59]. It might be possible to obtain enough micro-CT data to compare bone of young Black and White women at equally marginal levels of $25(\mathrm{OH}) \mathrm{D}$ and calcium restriction. The margins for vitamin
$\mathrm{D}$ and calcium for such a comparison are likely to be serum $25(\mathrm{OH}) \mathrm{D}$ below $25 \mathrm{nmol} / \mathrm{L}$, and a dietary calcium intake below $500 \mathrm{mg} /$ day $[19,60]$. In this modern era, with readily available sources of both vitamin $\mathrm{D}$ and calcium nutrition for all who live in the north, the compromises of past millennia are less evident in terms of rickets or pelvic disproportion. However, although nutritional osteomalacia has been presumed to be rare in modern society $[19,60]$, this may be due to the inability to detect it. The biopsy data from the German population, as published by Priemel et al., imply that osteomalacia at the pelvis is disconcertingly common in people with 25(OH)D below $75 \mathrm{nmol} / \mathrm{L}$ [50].

\section{Conclusion}

A sense as to why differences exist between the bones of Blacks and Whites may help in developing better research questions. The arguments presented here are an attempt to explain why the osteoporosis-related vitamin D paradox exists. I have tried to approach the problem from the perspective of anthropology and natural selection. Since anthropology is an empirical science, it is not readily amenable to the experimental and clinical methodologies generally expected in medicine. Research to test the present pelvic hypothesis to account for the vitamin D paradox could involve bioengineering analysis of pelvic bone, with adjustments for effects of rickets and osteomalacia. Emerging micro-CT technology could be used to compare matrix mineral density between young Black and White women matched for serum $25(\mathrm{OH}) \mathrm{D}$ and dietary calcium intake. Lastly the search for genetic insights could focus on variants selected to construct less bone matrix or to make the pelvis mineralize more quickly.

Based on the evidence presented here, the hypothesis is that Whites are more prone to osteoporosis later in life, because of the compromise during growth early in life, to accommodate for diminished amounts of calcium absorbed via the gut. The female pelvis is by far the most important part of the skeleton in terms of "fitness" for producing offspring. In terms of natural selection, the suitability of the pelvis for a vaginal birth took priority over the health of all other bones - to the point of increasing the eventual risk of osteoporosis. Just as skin color adapted to become whiter than that of the parent, Black population in Africa, bone and mineral metabolism also adapted with less total amount of bone, and faster mineralization of osteoid. In the face of less sunshine-derived vitamin $\mathrm{D}$, these metabolic adaptations made more efficient use of the diminished calcium absorbed from the diet, by making pelvic bone stiffer and less susceptible to deformation, thereby making Whites are more "fit" for non-tropical environments. But the cost of that fitness to reproduce was weaker bone later in life and greater risk of osteoporosis. 


\section{Compliance with ethical standards}

Conflict of interest None.

Open Access This article is distributed under the terms of the Creative Commons Attribution-NonCommercial 4.0 International License (http:// creativecommons.org/licenses/by-nc/4.0/), which permits any noncommercial use, distribution, and reproduction in any medium, provided you give appropriate credit to the original author(s) and the source, provide a link to the Creative Commons license, and indicate if changes were made.

\section{References}

1. Barrett-Connor E, Siris ES, Wehren LE et al (2005) Osteoporosis and fracture risk in women of different ethnic groups. J Bone Miner Res 20:185-194. https://doi.org/10.1359/JBMR.041007

2. Gutiérrez OM, Farwell WR, Kermah D, Taylor EN (2011) Racial differences in the relationship between vitamin $\mathrm{D}$, bone mineral density, and parathyroid hormone in the National Health and Nutrition Examination Survey. Osteoporos Int 22:1745-1753. https://doi.org/10.1007/s00198-010-1383-2

3. Luckey MM, Meier DE, Mandeli JP et al (1989) Radial and vertebral bone density in white and black women: evidence for racial differences in premenopausal bone homeostasis. J Clin Endocrinol Metab 69:762-770. https://doi.org/10.1210/jcem-69-4-762

4. Clemens TL, Adams JS, Henderson SL, Holick MF (1982) Increased skin pigment reduces the capacity of skin to synthesise vitamin D3. Lancet 1:74-76. https://doi.org/10.1016/s01406736(82)90214-8

5. Matsuoka LY, Wortsman J, Haddad JG et al (1991) Racial pigmentation and the cutaneous synthesis of vitamin D. Arch Dermatol 127:536-538. https://doi.org/10.1001/archderm.1991. 04510010104011

6. Seeman E (1998) Growth in bone mass and size-are racial and gender differences in bone mineral density more apparent than real? J Clin Endocrinol Metab 83:1414-1419. https://doi.org/10.1210/ jcem.83.5.4844

7. Aloia J, Mikhail M, Dhaliwal R et al (2015) Free 25(OH)D and the vitamin D paradox in African Americans. J Clin Endocrinol Metab 100:3356-3363. https://doi.org/10.1210/JC.2015-2066

8. Brown LL, Cohen B, Tabor D et al (2018) The vitamin D paradox in Black Americans: a systems-based approach to investigating clinical practice, research, and public health - expert panel meeting report. BMC Proc 12:6. https://doi.org/10.1186/s12919-018-01024

9. Nelson DA (2019) Evolutionary origins of the differences in osteoporosis risk in US populations. J Clin Densitom 22:301-304. https://doi.org/10.1016/j.jocd.2018.01.001

10. Powe CE, Evans MK, Wenger J et al (2013) Vitamin D-binding protein and vitamin D status of Black Americans and White Americans. N Engl J Med 369:1991-2000. https://doi.org/10. 1056/NEJMoa1306357

11. Hollis BW, Bikle DD (2014) Vitamin D-binding protein and vitamin D in blacks and whites. N Engl J Med 370:879-880. https://doi. org/10.1056/NEJMc1315850

12. Alzaman NS, Dawson-Hughes B, Nelson J et al (2016) Vitamin D status of black and white Americans and changes in vitamin D metabolites after varied doses of vitamin D supplementation. Am J Clin Nutr 104:205-214. https://doi.org/10.3945/ajen.115.129478
13. Ségurel L, Bon C (2017) On the evolution of lactase persistence in humans. Annu Rev Genomics Hum Genet 18:297-319. https://doi. org/10.1146/annurev-genom-091416-035340

14. Jablonski NG (2012) The evolution of human skin colouration and its relevance to health in the modern world. J R Coll Physicians Edinb 42:58-63. https://doi.org/10.4997/jrcpe.2012.114

15. Jablonski NG, Chaplin G (2013) Epidermal pigmentation in the human lineage is an adaptation to ultraviolet radiation. J Hum Evol 65:671-675. https://doi.org/10.1016/j.jhevol.2013.06.004

16. Luxwolda MF, Kuipers RS, Kema IP et al (2013) Vitamin D status indicators in indigenous populations in East Africa. Eur J Nutr 52: 1115-1125. https://doi.org/10.1007/s00394-012-0421-6

17. Luxwolda MF, Kuipers RS, Kema IP et al (2012) Traditionally living populations in East Africa have a mean serum 25hydroxyvitamin D concentration of $115 \mathrm{nmol} / \mathrm{l}$. Br J Nutr 108: 1557-1561. https://doi.org/10.1017/s0007114511007161

18. Vieth R (2003) Effects of vitamin D on bone and natural selection of skin color: how much vitamin D nutrition are we talking about? In: Agarwal SC, Stout SD (eds) Bone loss and osteoporosis: an anthropological perspective. Springer US, Boston, pp 139-154

19. Institute of Medicine Committee to Review Dietary Reference Intakes for Vitamin D, Calcium (2011) The National Academies Collection: reports funded by National Institutes of Health. In: Ross AC, Taylor CL, Yaktine AL, Del Valle HB (eds) Dietary reference intakes for calcium and vitamin D. National Academies Press (US) National Academy of Sciences, Washington (DC)

20. Hawkes K, O’Connell JF, Jones NGB et al (1998) Grandmothering, menopause, and the evolution of human life histories. Proc Natl Acad Sci U S A 95:1336-1339

21. Karasik D (2008) Osteoporosis: an evolutionary perspective. Hum Genet 124:349-356. https://doi.org/10.1007/s00439-008-0559-8

22. Relethford JH (1997) Hemispheric difference in human skin color. Am J Phys Anthropol 104:449-457. https://doi.org/10.1002/(SICI) 1096-8644(199712)104:4<449::AID-AJPA2>3.0.CO;2-N

23. Jablonski NG (2012) Human skin pigmentation as an example of adaptive evolution. Proc Am Philos Soc 156:45-57

24. Liu ES, Martins JS, Raimann A et al (2016) 1,25Dihydroxyvitamin D alone improves skeletal growth, microarchitecture, and strength in a murine model of XLH, despite enhanced FGF23 expression. J Bone Miner Res 31:929-939. https://doi.org/ 10.1002/jbmr.2783

25. Ikedo A, Ishibashi A, Matsumiya S et al (2016) Comparison of sitespecific bone mineral densities between endurance runners and sprinters in adolescent women. Nutrients 8:781. https://doi.org/10. 3390/nu8120781

26. Al-Shaar L, Nabulsi M, Maalouf J et al (2013) Effect of vitamin D replacement on hip structural geometry in adolescents: a randomized controlled trial. Bone 56:296-303. https://doi.org/10.1016/j. bone.2013.06.020

27. Arabi A, Tamim H, Nabulsi M et al (2004) Sex differences in the effect of body-composition variables on bone mass in healthy children and adolescents. Am J Clin Nutr 80:1428-1435. https://doi. org/10.1093/ajcn/80.5.1428

28. Kimball S, Fuleihan GE-H, Vieth R (2008) Vitamin D: a growing perspective. Crit Rev Clin Lab Sci 45:339-414. https://doi.org/10. 1080/10408360802165295

29. Stone PK (2016) Biocultural perspectives on maternal mortality and obstetrical death from the past to the present. Am J Phys Anthropol 159:S150-S171. https://doi.org/10.1002/ajpa.22906

30. Maxwell JP (1935) Further studies in adult rickets (osteomalacia) and foetal rickets: (section of obstetrics and gynaecology). Proc R Soc Med 28:265-300

31. Verbruggen SW, Nowlan NC (2017) Ontogeny of the human pelvis. Anat Rec 300:643-652. https://doi.org/10.1002/ar.23541

32. Dalstra M, Huiskes R (1995) Load transfer across the pelvic bone. J Biomech 28:715-724 
33. Dalstra M (1993) Biomechanical aspects of the pelvic bone and design criteria for acetabular prostheses. [Sl: sn]

34. Hunter GJ, Schneidau A, Hunter JV, Chapman M (1984) Rickets in adolescence. Clin Radiol 35:419-421. https://doi.org/10.1016/ S0009-9260(84)80207-X

35. Chaim W, Alroi A, Leiberman JR, Cohen A (1981) Severe contracted pelvis appearing after normal deliveries. Acta Obstet Gynecol Scand 60:131-134

36. Min CJ, Ehrenthal DB, Strobino DM (2015) Investigating racial differences in risk factors for primary cesarean delivery. Am J Obstet Gynecol 212:814.e1-814.e14. https://doi.org/10.1016/j. ajog.2015.01.029

37. Declercq E, Menacker F, Macdorman M (2006) Maternal risk profiles and the primary cesarean rate in the United States, 1991-2002. Am J Public Health 96:867-872. https://doi.org/10.2105/AJPH. 2004.052381

38. Scott-Wright AO, Flanagan TM, Wrona RM (1999) Predictors of cesarean section delivery among college-educated black and white women, Davidson County, Tennessee, 1990-1994. J Natl Med Assoc 91:273-277

39. Huesch M, Doctor JN (2015) Factors associated with increased cesarean risk among African American women: evidence from California, 2010. Am J Public Health 105:956-962. https://doi. org/10.2105/AJPH.2014.302381

40. Penfield CA, Lahiff M, Pies C, Caughey AB (2017) Adolescent pregnancies in the United States: how obstetric and sociodemographic factors influence risk of cesarean delivery. Am J Perinatol 34:123-129. https://doi.org/10.1055/s-0036-1584580

41. Wells JCK, DeSilva JM, Stock JT (2012) The obstetric dilemma: an ancient game of Russian roulette, or a variable dilemma sensitive to ecology? Am J Phys Anthropol 149(Suppl 55):40-71. https://doi. org/10.1002/ajpa.22160

42. Zengin A, Pye SR, Cook MJ et al (2016) Ethnic differences in bone geometry between White, Black and South Asian men in the UK. Bone 91:180-185. https://doi.org/10.1016/j.bone.2016.07.018

43. Warden SJ, Hill KM, Ferira AJ et al (2013) Racial differences in cortical bone and their relationship to biochemical variables in black and white children in the early stages of puberty. Osteoporos Int 24:1869-1879. https://doi.org/10.1007/s00198012-2174-8

44. Gilsanz V, Skaggs DL, Kovanlikaya A et al (1998) Differential effect of race on the axial and appendicular skeletons of children. J Clin Endocrinol Metab 83:1420-1427. https://doi.org/10.1210/ jcem.83.5.4765

45. Cummings SR, Cauley JA, Palermo L et al (1994) Racial differences in hip axis lengths might explain racial differences in rates of hip fracture. Osteoporos Int 4:226-229. https://doi.org/10.1007/ BF01623243

46. Popp KL, Xu C, Yuan A et al (2019) Trabecular microstructure is influenced by race and sex in Black and White young adults. Osteoporos Int 30:201-209. https://doi.org/10.1007/s00198-0184729-9

47. Schnitzler CM, Pettifor JM, Mesquita JM et al (1990) Histomorphometry of iliac crest bone in 346 normal Black and White South African adults. Bone Miner 10:183-199
48. Parisien M, Cosman F, Morgan D et al (1997) Histomorphometric assessment of bone mass, structure, and remodeling: a comparison between healthy Black and White premenopausal women. J Bone Miner Res 12:948-957. https://doi.org/10.1359/jbmr.1997.12.6. 948

49. Aloia JF (2008) African Americans, 25-hydroxyvitamin D, and osteoporosis: a paradox. Am J Clin Nutr 88:545S-550S. https:// doi.org/10.1093/ajen/88.2.545S

50. Priemel M, von Domarus C, Klatte TO et al (2010) Bone mineralization defects and vitamin D deficiency: histomorphometric analysis of iliac crest bone biopsies and circulating 25-hydroxyvitamin $\mathrm{D}$ in 675 patients. J Bone Miner Res Off J Am Soc Bone Miner Res 25:305-312. https://doi.org/10.1359/jbmr.090728

51. Maxmen A (2011) Nutrition advice: the vitamin D-lemma. Nature 475:23-25. https://doi.org/10.1038/475023a

52. Vieth R, Holick MF (2018) Chapter 57B - the IOM-Endocrine Society controversy on recommended vitamin D targets: in support of the Endocrine Society position. In: Feldman D (ed) Vitamin D (fourth edition). Academic press, pp 1091-1107

53. Bodnar LM, Platt RW, Simhan HN (2015) Early-pregnancy vitamin D deficiency and risk of preterm birth subtypes. Obstet Gynecol 125:439-447. https://doi.org/10.1097/aog.0000000000000621

54. Wagner CL, Baggerly C, McDonnell S et al (2016) Post-hoc analysis of vitamin D status and reduced risk of preterm birth in two vitamin D pregnancy cohorts compared with South Carolina March of Dimes 2009-2011 rates. J Steroid Biochem Mol Biol 155:245251. https://doi.org/10.1016/j.jsbmb.2015.10.022

55. Li Y, Aparicio C (2013) Discerning the subfibrillar structure of mineralized collagen fibrils: a model for the ultrastructure of bone. PLoS One 8:e76782. https://doi.org/10.1371/journal.pone.0076782

56. Karunaratne A, Esapa CR, Hiller J et al (2012) Significant deterioration in nanomechanical quality occurs through incomplete extrafibrillar mineralization in rachitic bone: evidence from in-situ synchrotron X-ray scattering and backscattered electron imaging. J Bone Miner Res 27:876-890. https://doi.org/10.1002/jbmr.1495

57. Dardenne O, Prud'Homme J, Hacking SA et al (2003) Rescue of the pseudo-Vitamin D deficiency rickets phenotype of CYP27B1deficient mice by treatment with 1,25-dihydroxyvitamin D3: biochemical, histomorphometric, and biomechanical analyses. J Bone Miner Res 18:637-643. https://doi.org/10.1359/jbmr.2003.18.4. 637

58. Turner CH, Owan I, Brizendine EJ et al (1996) High fluoride intakes cause osteomalacia and diminished bone strength in rats with renal deficiency. Bone 19:595-601. https://doi.org/10.1016/S87563282(96)00278-5

59. Chiang CY, Zebaze R, Wang X-F et al (2018) Cortical matrix mineral density measured noninvasively in pre- and postmenopausal women and a woman with vitamin D-dependent rickets. J Bone Miner Res 33:1312-1317. https://doi.org/10.1002/jbmr.3415

60. SACN (2016) Scientific advisory committee on nutrition vitamin D and health. https://wwwgovuk/government/groups/scientificadvisory-committee-on-nutrition. Accessed 20 Dec 2016

Publisher's note Springer Nature remains neutral with regard to jurisdictional claims in published maps and institutional affiliations. 